\title{
MODEL KONSEPTUAL PENGEMBANGAN PELABUHAN PERIKANAN SAMUDERA BUNGUS SEBAGAI PUSAT PENDARATAN IKAN TUNA
}

\section{DEVELOPMENT CONCEPTUAL MODEL OF BUNGUS OCEANIC FISHING PORT AS TUNA FISH LANDING CENTER}

\author{
Suci Asrina Ikhsan ${ }^{1}$, Iin Solihin ${ }^{2}$, Tri Wiji Nurani ${ }^{2}$ \\ ${ }^{1}$ Program Studi Pemanfaatan Sumberdaya Perikanan, Sekolah Pascasarjana \\ ${ }^{2}$ Departemen Pemanfaatan Sumberdaya Perikanan, \\ Fakultas Perikanan dan Ilmu Kelautan, Institut Pertanian Bogor \\ Korespondensi : suciasrinaikhsan@gmail.com, iinsolikhin.psp46@gmail.com
}

\begin{abstract}
Development conceptual model of oceanic fishing port Bungus as landing tuna fish center was a system that involves various actors in development. The research objective had done were evaluation the performance of oceanic fishing port Bungus and create a conceptual models as tuna fish landing centers. Development of oceanic fishing port Bungus with soft system methodology (SSM), which saw the overall problems in fishing ports. The results of this study were four conceptual models to repair problems that occur in the present. The conceptual model was built by three aspects, the study of human resources and institutional aspects, service aspects, and facilities aspects. Implementation the conceptual models that can be done with a variety strategies, involving the entire actors such as government, fishermen and the processing industry.
\end{abstract}

Keyword: Bungus port, development of fishing port, the conceptual model, the soft system

\section{ABSTRAK}

Model konseptual pengembangan pelabuhan perikanan samudera Bungus sebagai pusat pendaratan ikan tuna adalah sebuah sistem yang melibatkan berbagai aktor dalam pembangunan. Tujuan penelitian yang dilakukan adalah evaluasi kinerja pelabuhan perikanan samudera Bungus dan menciptakan model konseptual sebagai pusat pendaratan ikan tuna. Pengembangan pelabuhan perikanan samudera Bungus dengan soft system methodology (SSM), yang melihat masalah secara keseluruhan di pelabuhan perikanan. Hasil penelitian ini adalah empat model konseptual untuk memperbaiki masalah yang terjadi di masa sekarang. Model konseptual dibangun oleh tiga aspek, aspek tentang sumber daya manusia dan aspek kelembagaan, aspek pelayanan, dan aspek fasilitas. Implementasi model konseptual yang dapat dilakukan dengan berbagai strategi, yang melibatkan seluruh pelaku seperti pemerintah, nelayan dan industri pengolahan.

Kata kunci: metodologi sistem lembut, model konseptual, pelabuhan Bungus, pengembangan

\section{PENDAHULUAN}

Salah satu pelabuhan perikanan samudera di Indonesia adalah Pelabuhan Perikanan Samudera Bungus, terletak di Provinsi Sumatera Barat. Pelabuhan Perikanan Samudera Bungus telah menetapkan visinya yaitu menjadi "Pusat Pertumbuhan dan Pembangunan Ekonomi Perikanan Indonesia Bagian Barat" dengan menetapkan tujuan sebagai "Sentra Tuna Indonesia Bagian Barat" (PPS Bungus 2015). PPS Bungus untuk mencapai tujuan tersebut PPS Bungus telah dilengkapi dengan berbagai fasilitas, namun belum diketahui apakah PPS Bungus telah berfungsi secara optimal. Hal ini menjadi latar belakang untuk dilakukannya evaluasi terhadap kinerja PPS Bungus terkait dengan permasalahan yang kompleks.

Penelitian ini bertujuan untuk mengevaluasi kinerja PPS Bungus dan membuat model konseptual pengembangan PPS Bungus sebagai pusat pendaratan ikan tuna. Kinerja pelabuhan mencakup banyak aspek diantaranya terkait dengan aspek pihak pengelola pelabuhan, pelayanan dan fasilitas. Soft system methodology digunakan sebagai pendekatan mengatasi permasalahan yang kompleks. Pendekatan soft systems dianggap sebagai metodologi yang sangat produktif untuk mempelajari 
setiap aktivitas manusia yang terorganisir dalam mencapai tujuan-tujuan tertentu (Hidayatullah 2011).

\section{METODE PENELITIAN}

Penelitian lapang telah dilaksanakan di PPS Bungus, Padang, Provinsi Sumatera Barat. Waktu pelaksanaan penelitian ini dari bulan Maret-September 2016.

\section{Pendekatan Soft System Methodology (SSM)}

Menurut Checkland \& Poulter (2006), SSM dapat dilakukan melalui beberapa tahap yang terdiri dari tujuh tahap. Rincian dari masing-masing tahap sebagai berikut: a) tahap satu dan dua, pemahaman situasi masalah yang hasilnya digambarkan dengan rich picture; b) tahap tiga, menetapkan root definitions untuk mengatasi permasalahan yang telah dirumuskan; c) tahap empat, membuat model konseptual berdasarkan root definitions; d) tahap lima, membandingkan model konseptual dengan keadaan di dunia nyata; e) tahap enam, menetapkan perubahan yang layak; f) tahap tujuh, melakukan tindakan untuk memperbaiki situasi masalah. Penelitian ini melakukan empat tahap pendekatan SSM. Pendekatan SSM juga menghasilkan model konseptual yang dapat dijadikan salah satu acuan dalam memperbaiki sistem yang ada (Rahmah et al. 2013).

\section{Pengungkapan situasi masalah}

Pengungkapan situasi masalah dilakukan melalui observasi lapang, analisis data statistik, analisis intervensi, sosial dan politik. Analisis intervensi, sosial, politik dilakukan melalui wawancara mendalam dengan stakeholder, yaitu kepala Pelabuhan Perikanan Samudera Bungus, kepala Dinas Perikanan dan Kelautan Provinsi Sumatera Barat, pengelola pelabuhan perikanan, nelayan tuna, perusahaan pengolahan tuna, dan perusahaan pendukung untuk perbekalan melaut. Analisis intervensi adalah proses identifikasi aktor-aktor yang ada dalam fakta lapangan yang akan menjadi rujukan, serta peran mereka dalam fakta lapangan. Analisis intervensi melibatkan aktor sebagai client $(\mathrm{C})$, practitioner $(\mathrm{P})$, dan problem owner (PO) (Checkland \& Poulter 2006). Sementara itu, analisis sosial merupakan proses menganalisis peran, norma, dan nilai masing-masing aktor pada problem owner. Adapun analisis politik merupakan proses menganalisis kekuatan yang powerful dalam memutuskan terjadi atau tidaknya sesuatu hal. Analisis politik terfokus pada dua hal yaitu disposition of power dan nature of power. Pengungkapan situasi masalah yang digambarkan dengan rich picture.

\section{Analisis Root Definitions (RDs)}

RootDefinitions (RDs) ditetapkan untuk mengatasi permasalahan. RDs tersebut perlu diuji dan disempurnakan dengan alat bantu analisis CATWOE (customers, actors, transformation, worldview, owners, dan environmental constraints). Berdasarkan analisis CATWOE dan kriteria 3E (efficacy, efficiensy, dan effectiveness), didapatkan RDs dalam menggambarkan sistem. Daftar atau checklist CATWOE dan tiga kriteria adalah bagaimana proses transformasi ini sebaiknya dilaksanakan.

\section{Model konseptual}

RDs yang telah ditetapkan sebagai dasar untuk pembuatan model konseptual. Model konseptual untuk pengembangan PPS Bungus sebagai pusat pendaratan ikan tuna. Model konseptual dibuat berdasarkan gagasan peneliti.

\section{HASIL DAN PEMBAHASAN}

\section{Pengungkapan Situasi Masalah}

Provinsi Sumatera Barat secara geografis berada pada letak wilayah yang strategis. PPS Bungus diproyeksikan dan diharapkan dapat menjadi sentra ikan tuna Indonesia Bagian Barat. Kinerja suatu pelabuhan dapat dilihat dari aktivitas kapal perikanan pada Tabel 1 .

Adanya kebijakan PERMEN Nomor 30 tahun 2012 tentang usaha perikanan tangkap di wilayah pengelolaan perikanan negara Republik Indonesia pada pasal 37 ayat (3) bahwa setiap kapal penangkap ikan diberikan 1 (satu) pelabuhan pangkalan dan 1 (satu) pelabuhan singgah; ayat (4) setiap kapal pengangkut ikan diberikan 1 (satu) pelabuhan pangkalan; dan ayat (5) setiap kapal penangkap ikan dan kapal pengangkut ikan wajib mendaratkan ikan hasil tangkapan di pelabuhan pangkalan sebagaimana tercantum dalam SIPI (Surat Izin Penangkapan Ikan) atau SIKPI (Surat Izin Kapal Pengangkut Ikan). Kebijakan 
PERMEN tersebut mengakibatkan terjadinya penurunan kedatangan kapal untuk mendaratkan ikan di PPS Bungus. Penurunan perbaikan kapal (docking) disebabkan adanya lokasi docking kapal yang baru di daerah Kabupaten Pesisir Selatan yang menjadi alternatif bagi nelayan lainnya.

Produksi ekspor ikan tuna pada Tabel 2 adalah ikan tuna segar dan ikan tuna olahan. Harga ikan tuna segar lebih mahal daripada ikan tuna olahan, maka hal ini akan sangat berpengaruh terhadap nilai produksi ekspor ikan tuna. Produksi dan nilai produksi ekspor ikan tuna di PPS Bungus yang paling tinggi adalah tahun 2012, karena ikan tuna yang didaratkan yaitu jenis ikan tuna segar untuk ekspor ke Amerika dan Jepang.

Analisis intervensi melibatkan aktor sebagai client (C): peneliti dan pakar; practitioner $(\mathrm{P})$ : peneliti; dan problem owners (PO): stakeholder. Adapun pemerintah, pengelola pelabuhan perikanan, dan pelaku usaha merupakan problem solver dan problem owner pada kegiatan pemanfaatan tersebut. Masing-masing aktor pada problem ownermemiliki peran, norma, dan nilai, serta disposition of power dan nature of power. Hasil dari pemahaman terhadap situasi permasalahan terhadap permasalahaan di PPS Bungus yang dikelompokkan ke dalam aspek sumberdaya manusia dan kelembagaan, aspek pelayanan dan aspek fasilitas. Permasalahan tersebut terdapat pada Tabel 3 .

Permasalahan yang terdapat di PPS Bungus dengan mentabulasikan selanjutnya digambarkan melalui rich picture yang terdapat pada Gambar 1 . Setiap permasalahan digambarkan dalam skema dengan tiga aspek. Permasalahan pengembangan PPS Bungus sebagai pusat pendaratan ikan tuna yang telah disebutkan pada Tabel 3 diatasi melalui RDs.

Tabel 1. Aktivitas kapal perikanan di PPS Bungus tahun 2011-2015

\begin{tabular}{|c|c|c|c|c|c|}
\hline \multirow{2}{*}{ Kegiatan/Activity } & \multicolumn{5}{|c|}{ Tahun/ Year (Unit) } \\
\hline & 2011 & 2012 & 2013 & 2014 & 2015 \\
\hline Mendaratkan ikan/Land fish & 249 & 247 & 306 & 266 & 226 \\
\hline $\begin{array}{l}\text { Mengisi perbekalan solar/Fill the solar } \\
\text { supply }\end{array}$ & 416 & 712 & 961 & 822 & 741 \\
\hline $\begin{array}{l}\text { Mengisi perbekalan air / Fill up the } \\
\text { water supply }\end{array}$ & 449 & 746 & 800 & 649 & 548 \\
\hline Mengisi perbekalan es / Fill ice supply & 1.266 & 716 & 800 & 975 & 2.558 \\
\hline Perbaikan kapal/Ship repair & 330 & 377 & 430 & 417 & 369 \\
\hline Total & 2.710 & 2.798 & 3.297 & 3.129 & 4.442 \\
\hline
\end{tabular}

Sumber/Source : PPS Bungus (2016) / PPS Bungus (2016)

Tabel 2. Produksi dan nilai produksi ekspor ikan tuna di PPS Bungus

\begin{tabular}{ccrr}
\hline No. & Tahun/Year & $\begin{array}{c}\text { Produksi/ } \\
\text { Production (kg) }\end{array}$ & $\begin{array}{c}\text { Nilai Produksi/ } \\
\text { Production value (Rp) }\end{array}$ \\
\hline 1. & 2011 & 730.601 & 53.853 .478 .000 \\
2. & 2012 & 998.397 & 89.501 .143 .500 \\
3. & 2013 & 768.534 & 50.549 .767 .290 \\
4. & 2014 & 871.854 & 52.766 .667 .631 \\
5. & 2015 & 508.223 & 30.515 .341 .800 \\
\hline \multicolumn{4}{r}{} \\
\hline
\end{tabular}

Sumber/Source : PPS Bungus (2016) / PPS Bungus (2016) 


\begin{tabular}{|c|c|c|}
\hline No. & $\begin{array}{c}\text { Aspek Kajian/Aspects } \\
\text { of the study }\end{array}$ & Permasalahan/Problems \\
\hline 1. & $\begin{array}{l}\text { Aspek sumberdaya } \\
\text { manusia dan } \\
\text { kelembagaan/ } \\
\text { Human resources and } \\
\text { institutional aspects }\end{array}$ & $\begin{array}{l}\text { - Rendahnya koordinasi antara pemerintah daerah } \\
\text { dengan pemerintah pusat (PPS Bungus)/Low level of } \\
\text { coordination among regional government with the cen- } \\
\text { tral government (PPS Bungus). } \\
\text { Kelembagaan hanya menjalankan peran mereka mas- } \\
\text { ing-masing dalam pengelolaan perikanan di Sumatera } \\
\text { Barat/The institutional just be work with self idea. } \\
\text { - Rendahnya investor perikanan tuna dan industri } \\
\text { pendukung lainnya di Sumatera Barat/The low inves- } \\
\text { tor fisheries for tuna and supporting industries in West } \\
\text { Sumatera. } \\
\text { Rendahnya sumberdaya pengelola PPS Bungus / Low } \\
\text { resource manager in PPS Bungus. }\end{array}$ \\
\hline 2. & $\begin{array}{l}\text { Aspek pelayanan/ } \\
\text { Services aspects }\end{array}$ & $\begin{array}{l}\text { - Frekuensi kedatangan kapal untuk bongkar muat } \\
\text { masih rendah di PPS Bungus/The frequency of landing } \\
\text { ship has low. } \\
\text { - SIUP dan SIKPI yang dikeluarkan dari PPS Bungus } \\
\text { masih rendah oleh investor kapal tuna/SIUP and } \\
\text { SIKPI passed by PPS Bungus very low. } \\
\text { Masih adanya penggandaan Surat Izin Berlayar yang } \\
\text { dilakukan oleh nelayan di PPS Bungus / Duplicate for } \\
\text { the letter permission. } \\
\text { - Ketidaktahuan nelayan akan keberadaan syahbandar } \\
\text { di PPS Bungus / Fisherman was not know office. }\end{array}$ \\
\hline 3. & $\begin{array}{l}\text { Aspek fasilitas / Facili- } \\
\text { ties aspects }\end{array}$ & $\begin{array}{l}\text { - Tingkat pemanfaatan fasilitas pelabuhan yang masih } \\
\text { rendah seperti dermaga dan kolam pelabuhan yang } \\
\text { belum optimal dimanfaatkan/The level of utilization of } \\
\text { the port facilities are still low. } \\
\text { - } \text { Fasilitas pelabuhan yang masih kurang baik untuk } \\
\text { mendaratkan hasil tangkapan (basket, bollard } \\
\text { dermaga) / Port facilities are still less well to land } \\
\text { catches. } \\
\text { Tingkat aksesibilitas pelabuhan perikanan untuk } \\
\text { pendaratan tuna masih kurang baik/ The accessibility } \\
\text { level of the fishing port for landing tuna still } \\
\text { unfavourable. } \\
\text { Keberadaan industri pengolah tuna yang masih } \\
\text { sedikit dan industri pendukung yang masih belum } \\
\text { ada di PPS Bungus / The existence of a tuna-processing } \\
\text { industry was stilled a bit of supported industry and } \\
\text { there was not stilled in PPS Bungus. } \\
\text { Potensi kemudahan pemasaran yang meliputi } \\
\text { keberadaan industri pengolahan, eksportir dan akses } \\
\text { pasar belum memenuhi dengan baik/The potential of } \\
\text { marketing that includes the existence of the processing } \\
\text { industry, exporters and market access was not meet } \\
\text { properly. } \\
\text { Lahan pelabuhan yang masih banyak kosong untuk } \\
\text { disewakan kepada pelaku usaha/Land ports were } \\
\text { stilled empty lots for rent to businessmen. }\end{array}$ \\
\hline
\end{tabular}




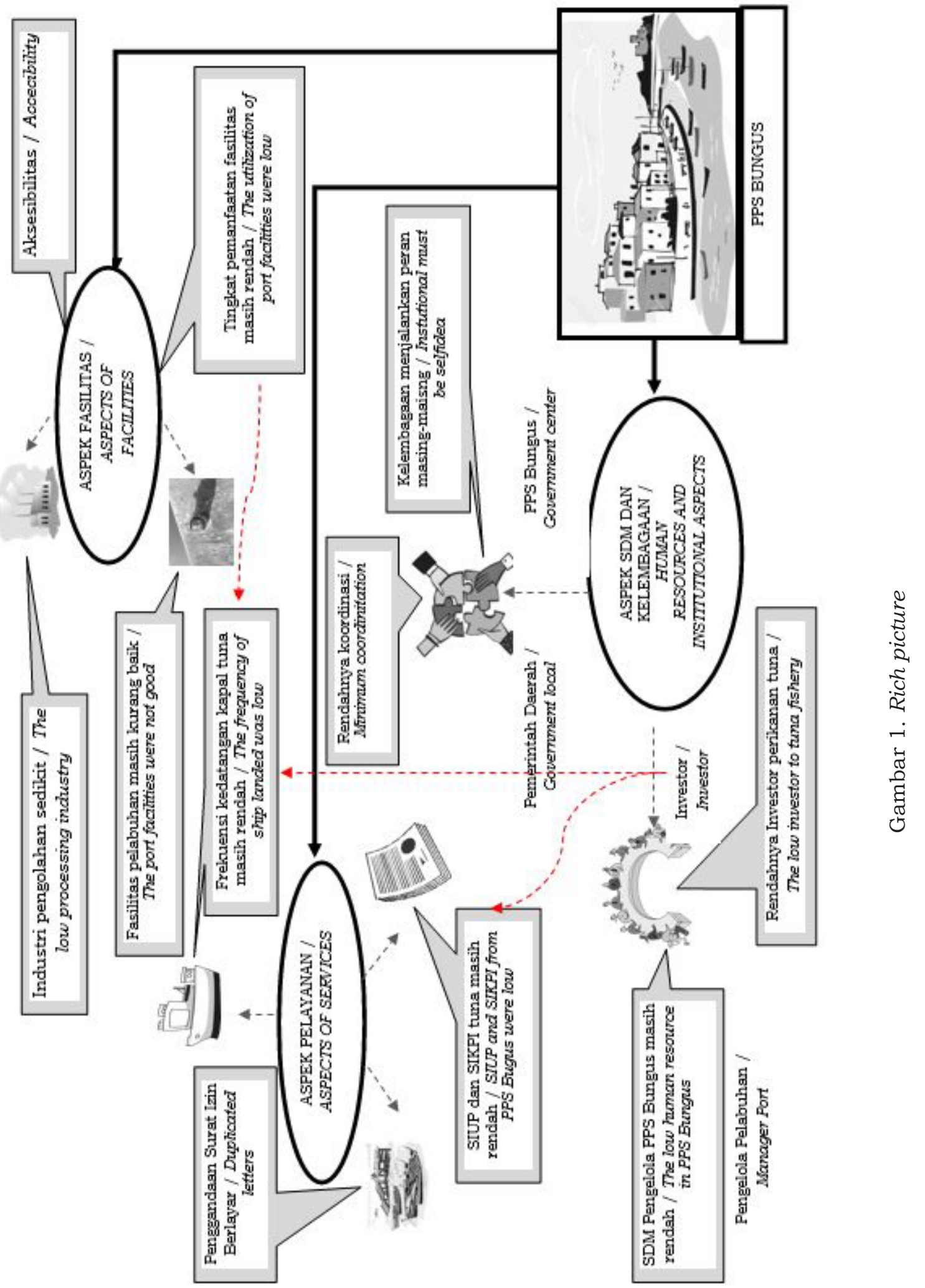




\section{Root Definitions (RDs)}

Tahap penyusunan definisi permasalahan dan pembuatan model konseptual merupakan bagian tahap berpikir sistem tentang dunia nyata pada pendekatan SSM. Tahap penyusunan definisi permasalahan menghasilkan RDs yang merupakan cara menggambarkan sistem untuk membantu proses permodelan sistem pada tahap pembuatan model konseptual. RDs yang telah dihasilkan yaitu :

- Root definition 1, peningkatan kualitas sumberdaya manusia pengelola pelabuhan untuk dapat memberikan pelayanan yang baik melalui peningkatan kapasitas dan kapabilitas sumberdaya manusia.

- Root definition 2, peningkatan koordinasi antar lembaga/antar sektor untuk dapat melakukan pengembangan secara integrasi.

- Root definition 3, peningkatan/menarik kapal tuna untuk masuk ke PPS Bungus melalui kesiapan fasilitas pelabuhan agar tercapainya optimalisasi penggunaan fasilitas sebagai pusat pendaratan ikan tuna.

- Root definition 4, pengembangan dan pengoptimalisasikan lahan pelabuhan untuk industri serta penyediaan fasilitas melalui kerjasama dengan pihak swasta.

RDs yang disusun benar-benar dapat digunakan sebagai dasar pembuatan model konseptual, maka RDs tersebut pelu diuji dan disempurnakan dengan alat bantu analisis CATWOE (customers, actors, transformation, weltanschauung atau worldview, owners, dan environmental constraints). Alat bantu CATWOE ini merupakan alat bantu pengingat (memotic) supaya RDs yang dibuat benar-benar menggambarkan sebuah sistem aktivitas manusia yang relevan yang kita pilih. Kemudian perlu dilanjutkan dengan pertanyaan kriteria pengukuran kinerja bekerjanya sistem aktivitas yang punya maksud tersebut, umumnya digunakan tiga criteria E (Efficacy, Effectiveness, dan Efficiency).

Berdasarkan analisis CATWOE dan kriteria 3E (efficacy, effectiveness, dan efficiency), didapatkan RDs dalam menggambarkan sistem. Daftar atau checklist CATWOE dan tiga kriteria adalah bagaimana proses transformasi ini sebaiknya dilaksanakan. RDs dianalisis melalui CATWOE dan 3E yang terdapat pada Tabel 4.

Tabel 4. CATWOE dan 3E

\begin{tabular}{|c|c|c|c|c|}
\hline \multirow[b]{2}{*}{$\begin{array}{l}\text { CATWOE } \\
\text { dan } 3 E\end{array}$} & \multicolumn{4}{|c|}{ Root Definitions } \\
\hline & $\begin{array}{l}\text { Peningkatan } \\
\text { kualitas sumberdaya } \\
\text { manusia pengelola } \\
\text { pelabuhan untuk } \\
\text { dapat memberikan } \\
\text { pelayanan yang } \\
\text { baik melalui } \\
\text { peningkatan kapasitas } \\
\text { dan kapabilitas } \\
\text { sumberdaya } \\
\text { manusia/Improving } \\
\text { the quality of human } \\
\text { resources manager } \\
\text { port to be able to } \\
\text { provide good services } \\
\text { through capacity } \\
\text { building and human } \\
\text { resource capabilities. } \\
\text { (Root definition 1) }\end{array}$ & $\begin{array}{l}\text { Peningkatan } \\
\text { koordinasi } \\
\text { antar } \\
\text { lembaga/ } \\
\text { antar sektor } \\
\text { untuk dapat } \\
\text { melakukan } \\
\text { pengembangan } \\
\text { secara } \\
\text { integrasi/ } \\
\text { Increasing the } \\
\text { coordination } \\
\text { between sector. } \\
\text { (Root definition } \\
\text { 2) }\end{array}$ & $\begin{array}{l}\text { Peningkatan/ } \\
\text { menarik kapal } \\
\text { tuna untuk masuk } \\
\text { ke PPS Bungus } \\
\text { melalui kesiapan } \\
\text { fasilitas pelabuhan } \\
\text { agar tercapainya } \\
\text { optimalisasi } \\
\text { penggunaan } \\
\text { fasilitas sebagai } \\
\text { pusat pendaratan } \\
\text { ikan tuna/ } \\
\text { Increasing to tuna } \\
\text { ship in enter PPS } \\
\text { Bungus with ready } \\
\text { facilities. } \\
\text { (Root definition 3) }\end{array}$ & $\begin{array}{l}\text { Pengembangan dan } \\
\text { pengoptimalisasikan } \\
\text { lahan pelabuhan } \\
\text { untuk industri serta } \\
\text { penyediaan fasilitas } \\
\text { melalui kerjasama } \\
\text { dengan pihak } \\
\text { swasta/ Development } \\
\text { and optimalizatiton } \\
\text { to industry with } \\
\text { team work. } \\
\text { (Root definition 4) }\end{array}$ \\
\hline Customers & $\begin{array}{l}\text { Pemerintah pusat dan } \\
\text { daerah serta pelaku } \\
\text { usaha/Center and } \\
\text { local governments, } \\
\text { bussinesman. }\end{array}$ & $\begin{array}{l}\text { Pemerintah } \\
\text { pusat dan } \\
\text { daerah } \\
\text { serta pelaku } \\
\text { usaha/Center } \\
\text { and local } \\
\text { governments, } \\
\text { bussinesman. }\end{array}$ & $\begin{array}{l}\text { Pemerintah pusat } \\
\text { dan daerah serta } \\
\text { pelaku usaha/ } \\
\text { Center and local } \\
\text { governments, } \\
\text { bussinesman. }\end{array}$ & $\begin{array}{l}\text { Pemerintah pusat } \\
\text { dan daerah serta } \\
\text { pelaku usaha/ } \\
\text { Center and local } \\
\text { governments, } \\
\text { bussinesman. }\end{array}$ \\
\hline
\end{tabular}


Lanjutan Tabel 4. CATWOE dan 3E

\begin{tabular}{|c|c|c|c|c|}
\hline & \multicolumn{4}{|c|}{ Root Definitions } \\
\hline Actors & $\begin{array}{l}\text { Pelaku usaha dan } \\
\text { nelayan/Bussinesman } \\
\text { and fisherman. }\end{array}$ & $\begin{array}{l}\text { Pemerintah } \\
\text { pusat dan } \\
\text { daerah/Center } \\
\text { and local } \\
\text { governments. }\end{array}$ & $\begin{array}{l}\text { Pelaku usaha/ } \\
\text { Bussinesman. }\end{array}$ & $\begin{array}{l}\text { Pemerintah pusat } \\
\text { dan daerah serta } \\
\text { pelaku usaha/ } \\
\text { Center and local } \\
\text { governments. }\end{array}$ \\
\hline Transformasi & $\begin{array}{l}\text { Peningkatan kualitas } \\
\text { sumberdaya manusia/ } \\
\text { Increase of quality } \\
\text { resource human. }\end{array}$ & $\begin{array}{l}\text { Peningkatan } \\
\text { interaksi dan } \\
\text { kerja sama/ } \\
\text { Increase of } \\
\text { interaction and } \\
\text { teamwork. }\end{array}$ & $\begin{array}{l}\text { Kedatangan kapal } \\
\text { tuna : dari rendah } \\
\text { ke tinggi/Tuna ship } \\
\text { will be highest. }\end{array}$ & $\begin{array}{l}\text { Optimalisasi } \\
\text { fasilitas : dari } \\
\text { rendah ke } \\
\text { tinggi/The } \\
\text { increase facility } \\
\text { optimalization. }\end{array}$ \\
\hline Worldview & $\begin{array}{l}\text { Keberpihakan } \\
\text { pemerintah } \\
\text { terhadap kapasitas } \\
\text { dan kapabilitas } \\
\text { sumberdaya } \\
\text { manusia untuk } \\
\text { dapat melaksanakan } \\
\text { pelayanan yang } \\
\text { baik/ Capacity and } \\
\text { capability for resource } \\
\text { human to better } \\
\text { service. }\end{array}$ & $\begin{array}{l}\text { Pemahaman } \\
\text { antar } \\
\text { lembaga/antar } \\
\text { instansi untuk } \\
\text { membangun } \\
\text { perikanan } \\
\text { tuna/ } \\
\text { Understanding } \\
\text { between } \\
\text { institutional. }\end{array}$ & $\begin{array}{l}\text { Fasilitas yang } \\
\text { cukup dan dapat } \\
\text { beroperasional, } \\
\text { ketersediaan sarana } \\
\text { dan prasarana } \\
\text { pelabuhan, serta } \\
\text { infrastruktur } \\
\text { pelabuhan yang } \\
\text { cukup/ Best facility } \\
\text { and be better } \\
\text { operational. }\end{array}$ & $\begin{array}{l}\text { Tersedianya } \\
\text { lahan pelabuhan } \\
\text { untuk industri } \\
\text { perikanan/Land } \\
\text { port to fishery } \\
\text { industry. }\end{array}$ \\
\hline Owners & $\begin{array}{l}\text { Pemerintah pusat dan } \\
\text { daerah/Center and } \\
\text { local governments. }\end{array}$ & $\begin{array}{l}\text { Pemerintah } \\
\text { pusat dan } \\
\text { daerah/Center } \\
\text { and local } \\
\text { governments. }\end{array}$ & $\begin{array}{l}\text { Pemerintah pusat } \\
\text { dan daerah/ } \\
\text { Center and local } \\
\text { governments. }\end{array}$ & $\begin{array}{l}\text { Pemerintah pusat } \\
\text { dan daerah/ } \\
\text { Center and local } \\
\text { governments. }\end{array}$ \\
\hline Environment & $\begin{array}{l}\text { Dukungan Menteri } \\
\text { Kelautan dan } \\
\text { Perikanan, Gubernur } \\
\text { Sumatera Barat, } \\
\text { ketersediaan anggaran } \\
\text { dan sumber daya/ } \\
\text { Supporting from } \\
\text { minister, governor and } \\
\text { source funding. }\end{array}$ & $\begin{array}{l}\text { Dukungan } \\
\text { Menteri } \\
\text { Kelautan dan } \\
\text { Perikanan, } \\
\text { Gubernur } \\
\text { Sumatera } \\
\text { Barat, } \\
\text { ketersediaan } \\
\text { anggaran dan } \\
\text { sumber daya/ } \\
\text { Supporting } \\
\text { from minister, } \\
\text { governor and } \\
\text { source funding. }\end{array}$ & $\begin{array}{l}\text { Dukungan } \\
\text { Menteri Kelautan } \\
\text { dan Perikanan, } \\
\text { Gubernur Sumatera } \\
\text { Barat, ketersediaan } \\
\text { anggaran dan } \\
\text { sumber daya/ } \\
\text { Supporting from } \\
\text { minister, governor } \\
\text { and source funding. }\end{array}$ & $\begin{array}{l}\text { Dukungan } \\
\text { Menteri Kelautan } \\
\text { dan Perikanan, } \\
\text { Gubernur } \\
\text { Sumatera Barat, } \\
\text { ketersediaan } \\
\text { anggaran dan } \\
\text { sumber daya/ } \\
\text { Supporting from } \\
\text { minister, governor } \\
\text { and source } \\
\text { funding. }\end{array}$ \\
\hline Efikasi (E1) & $\begin{array}{l}\text { Kualitas sumberdaya } \\
\text { yang meningkat } \\
\text { melalui interaksi } \\
\text { dengan lembaga/ The } \\
\text { quality resource to } \\
\text { increase for interaction. }\end{array}$ & $\begin{array}{l}\text { Interaksi } \\
\text { dan kerja } \\
\text { sama antar } \\
\text { pelaku usaha } \\
\text { dengan basis } \\
\text { keterlekatan/ } \\
\text { sinergi antar } \\
\text { lembaga/ } \\
\text { Interaction } \\
\text { between } \\
\text { institutional. }\end{array}$ & $\begin{array}{l}\text { Pelayanan yang } \\
\text { efektif dan efisien di } \\
\text { PPS Bungus sebagai } \\
\text { pusat pendaratan } \\
\text { ikan tuna/The } \\
\text { efectiveness service } \\
\text { at PPS Bungus as } \\
\text { landing center of } \\
\text { tuna fish. }\end{array}$ & $\begin{array}{l}\text { Optimalisasi } \\
\text { pemanfaatan } \\
\text { fasilitas yang } \\
\text { meningkat/The } \\
\text { optimalization for } \\
\text { facilities. }\end{array}$ \\
\hline
\end{tabular}




\begin{tabular}{|c|c|c|c|c|}
\hline \multirow[b]{2}{*}{$\begin{array}{l}\text { Efisiensi } \\
\quad(\mathrm{E} 2)\end{array}$} & \multicolumn{4}{|c|}{ Root Definitions } \\
\hline & $\begin{array}{l}\text { Menggunakan SDM, } \\
\text { sumber keuangan, } \\
\text { dan waktu yang } \\
\text { minimum/Human } \\
\text { resource, funding and } \\
\text { minimum timing. }\end{array}$ & $\begin{array}{l}\text { Menggunakan } \\
\text { SDM, sumber } \\
\text { keuangan, dan } \\
\text { waktu yang } \\
\text { minimum/ } \\
\text { Minimum } \\
\text { for resource } \\
\text { human, } \\
\text { funding and } \\
\text { timing. }\end{array}$ & $\begin{array}{l}\text { Menggunakan SDM, } \\
\text { sumber keuangan, } \\
\text { dan waktu yang } \\
\text { minimum/Minimum } \\
\text { for resource human, } \\
\text { funding and timing. }\end{array}$ & $\begin{array}{l}\text { Menggunakan SDM, } \\
\text { sumber keuangan, } \\
\text { dan waktu yang } \\
\text { minimum/Minimum } \\
\text { for resource human, } \\
\text { funding and timing. }\end{array}$ \\
\hline Efektif (E3) & $\begin{array}{l}\text { Tercapainya } \\
\text { peningkatan kualitas } \\
\text { sumberdaya manusia/ } \\
\text { The increase quality of } \\
\text { human resource. }\end{array}$ & $\begin{array}{l}\text { Tercapainya } \\
\text { sinergi antar } \\
\text { kelembagaan/ } \\
\text { The } \\
\text { achievement } \\
\text { for sinergy } \\
\text { each other. }\end{array}$ & $\begin{array}{l}\text { Tercapainya } \\
\text { peningkatan kapal } \\
\text { tuna masuk ke } \\
\text { PPS Bungus / The } \\
\text { achievement for ship } \\
\text { tuna enter in PPS } \\
\text { Bungus. }\end{array}$ & $\begin{array}{l}\text { Tercapainya } \\
\text { pemanfaatan lahan/ } \\
\text { The achievement for } \\
\text { land utilization. }\end{array}$ \\
\hline
\end{tabular}

\section{Model konseptual}

Hasil model konseptual pada pengembangan PPS Bungus sebagai pusat pendaratan ikan tuna dibuat berdasarkan RDs, yang terlihat pada Gambar 2 sampai Gambar 5. Root definition 1 terlihat pada Gambar 2 merupakan permasalahan sumberdaya manusia pengelola PPS Bungus dapat diatasi dengan peningkatan kapasitas dan kapabilitas. Agar tercapainya peningkatan tersebut maka dilakukan melalui pelatihan dan keterlibatan stakeholder.

Root definition 2 terlihat pada Gambar 3 merupakan permasalahan rendahnya koordinasi antar lembaga/antar sektor. Permasalahan dapat dilakukan melalui komunikasi dan pemahaman antar lembaga/antar sektor.

Root definition 3 terlihat pada Gambar 4 merupakan permasalahan rendahnya kapal tuna untuk masuk ke PPS Bungus dapat ditingkatkan melalui kesiapan fasilitas pelabuhan. Agar tercapainya optimalisasi penggunaan fasilitas sebagai pusat pendaratan ikan tuna melalui menarik investor kapal masuk ke PPS Bungus.

Root definition 4 terlihat pada Gambar 5 merupakan permasalahan rendahnya pengoptimalisasikan lahan pelabuhan untuk industri serta penyediaan fasilitas. Agar tercapainya pengoptimalisasi lahan dilakukan melalui kerjasama dengan pihak swasta.

Hasil evaluasi terhadap kinerja PPS Bungus diperoleh permasalahan pada aspek sumberdaya manusia dan kelembagaan, aspek pelayanan dan aspek fasilitas. Permasalahan pada aspek sumberdaya pengelola di PPS Bungus masih rendahnya kompetensi dan jumlah pegawai, sebagian besar pegawai merupakan pegawai kontrak yang terdiri dari latar belakang pendidikan yang belum sesuai. Root definition 1 yaitu PPS Bungus perlu meningkatkan kapasitas sumberdaya pengelola dan kapabilitas dengan pelatihan-pelatihan agar dapat memaksimalkan pelayanan yang baik. Hal tersebut ditunjukan juga dengan hasil penelitian Rahmawati et al. (2014), pengembangan pelabuhan telah dilakukan di PPN Brondong yang meliputi pengembangan fisik dan non fisik karena disesuaikan dengan kondisi yang ada dan tuntutan masyarakat. Pengembangan fisik mengacu pada master plan dan pengembangan non fisik dengan memberikan pelatihan-pelatihan kepada nelayan dan sumberdaya manusia (SDM) yang ada di lembaga.

Permasalahan kedua pada kelembagaan, yaitu rendahnya koordinasi antara pemerintah daerah dengan PPS Bungus. Kelembagaan/instansi hanya menjalankan peran mereka masing-masing dalam pengelolaan pelabuhan sebagai pusat pendaratan ikan tuna. Permasalahan tersebut dilakukan dengan root definition 2 yaitu peningkatan koordinasi antar lembaga/antar sektor untuk dapat melakukan pengembangan secara integrasi. Terjalinnya komunikasi antar lembaga dengan meningkatkan kemampuan bersama untuk memaksimalkan manfaat serta keuntungan sehingga akan terlaksananya peningkatan investasi dan akses modal 
untuk pencapaian upaya pengembangan PPS Bungus. Keterlibatan lembaga atau institusi serta peran dan fungsinya terkait implementasi kebijakan didalam sistem mempengaruhi terciptanya sistem harmonis dan iklim yang kondusif (Riyanto et al. 2014).

Permasalahan ketiga pada aspek pelayanan dengan rendahnya frekuensi kedatangan kapal untuk bongkar muat, hal ini berkaitan dengan kebijakan pemerintah serta rendahnya investor kapal tuna yang berasal dari PPS Bungus. Diniah et al. (2012), menyebutkan bahwa pelayanan yang diberikan oleh pihak pelabuhan pada umumnya adalah pelayanan yang terkait dengan operasional fasilitas, sehingga pada akhirnya dapat memenuhi kebutuhan pengguna pelabuhan. Adapun faktor penghambat yaitu ketersediaan industri pengolahan tuna, saat ini hanya terdapat satu industri pengolahan tuna yang dimiliki oleh Provinsi Sumatera Barat, serta juga industri pendukung belum tersedia. Investor untuk perikanan tuna yang masih sangat sedikit di PPS Bungus. Menurut Ruswandi \& Dewi (2013), salah satu penentu bagi pengembangan perekonomian di sekitar pelabuhan yaitu investasi di sekitar pelabuhan. Pengetahuan nelayan untuk keberadaan kantor pelayanan administrasi masih kurang baik dan masih adanya nelayan yang melakukan pelanggaran untuk penggandaan surat izin berlayar. Menurut Kresnanto (2004), tingkat operasional merupakan salah satu tolak ukur keberhasilan pengelolaan pelabuhan. Permasalahan tersebut dengan penetapan root definition 3 yaitu peningkatan/menarik kapal tuna untuk masuk ke PPS Bungus melalui kesiapan fasilitas pelabuhan agar tercapainya optimalisasi penggunaan fasilitas sebagai pusat pendarataan tuna. Permasalahan pada aspek fasilitas dengan masih rendahnya tingkat pemanfaatan fasilitas pelabuhan, keadaan fasilitas yang masih kurang baik, serta tingkat aksesibilitas pelabuhan perikanan untuk pendaratan ikan tuna yang masih kurang baik, potensi kemudahan pemasaran yang meliputi keberadaan industri pengolahan, eksportir dan akses pasar belum memenuhi dengan baik. Perikanan tuna membutuhkan pelabuhan perikanan yang lebih khusus dibandingkan dengan kegiatan perikanan lainnya.Kapalakanlebih mempertimbangkan kondisi pelabuhan dari sisi teknis seperti kondisi fisik pelabuhan dapat nyaman untuk berlabuh kapal, ketersediaan kebutuhan operasi penangkapan serta kemudahan pemasaran produk. Ukuran kapal yang besar mensyaratkan alur masuk kolam pelabuhan yang lebar, kedalaman kolam pelabuhan yang dalam dan fasilitas dermaga pelabuhan yang memadai. Tujuan utama hasil tangkapan produk tuna mensyaratkan adanya fasilitas penanganan ikan yang memadai untuk penanganan tuna segar, serta aksesibilitas yang baik menuju pelabuhan udara untuk pengangkutan ekspor (Nurani et al. 2010). Kualitas adalah syarat utama tuna untuk diekspor. Kualitas tuna dapat dipengaruhi oleh bagaimana ikan yang akan ditangkap, ditangani, mendarat, disimpan, dan didistribusikan. Proses penanganan tuna awal dari rantai produksi. Jika ada kesalahan dalam tahap ini, itu tidak dapat diperbaiki di tahap selanjutnya. Tuna dengan kualitas buruk akan ditolak karena tidak memenuhi kualitas ekspor. Oleh karena itu, tuna harga kualitas buruk akan jauh lebih rendah daripada produk yang memenuhi kualitas ekspor (Iskandar et al. 2010).

Permasalahan keempat yaitu rendahnya pemanfaatan lahan PPS Bungus oleh pihak swasta. Permasalahan tersebut diatasi dengan root definition 4 yaitu pengembangan dan pengoptimalisasikan lahan pelabuhan untuk industri serta penyediaan fasilitas melalui kerjasama dengan pihak swasta. Luas daratan PPS Bungus yaitu 16.6 ha dan luas perairan PPS Bungus 7.5 ha, lahan daratan yang masih terpakai hanya 2.6 ha dan sisa lahan masih ada 14 ha untuk pengembangan dan pengoptimalisasikan lahan pelabuhan. Peluang usaha yang bisa dikembangkan pada lahan PPS Bungus adalah pabrik cold storage yang belum tersedia; unit pengolahan berupa pengalengan, pengeringan dan tepung ikan; serta dock yard/slip way kapasitas 100 GT. Pelabuhan perikanan mempunyai peran yang sangat penting terhadap perikanan laut, karena merupakan center perekonomian mulai saat ikan didaratkan pasca penangkapan dari daerah penangkapan ikan sampai awal ikan dipasarkan di pelabuhan perikanan (Lubis 2011). Pelabuhan perikanan sebagai pusat ekonomi perikanan merupakan salah satu komponen penting dalam sistem perikanan tangkap yang perlu dimanfaatkan, diorganisisr dan dikelola dengan baik (Lubis \& Pane 2012). 


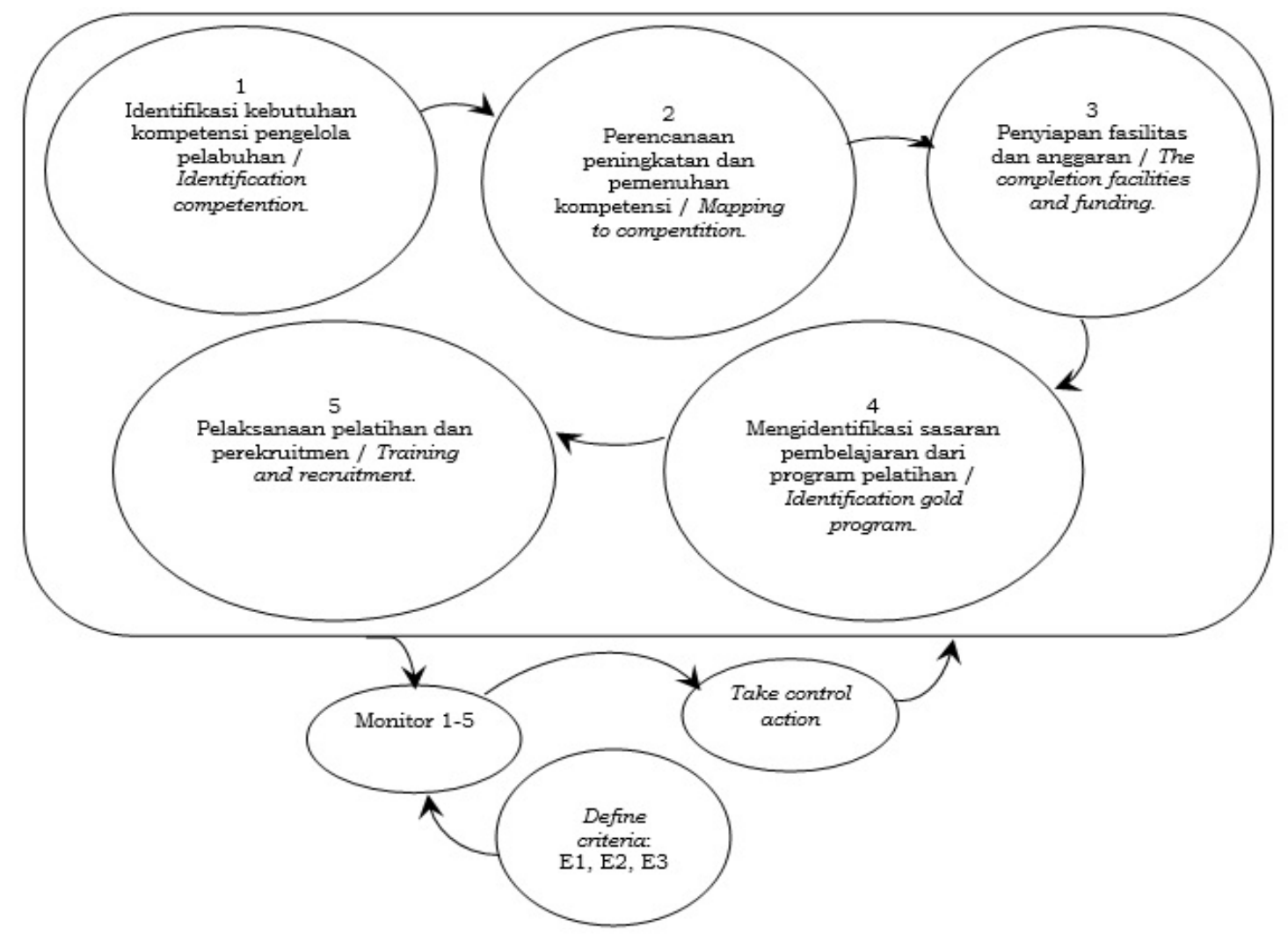

Gambar 2. Model konseptual peningkatan sumberdaya manusia

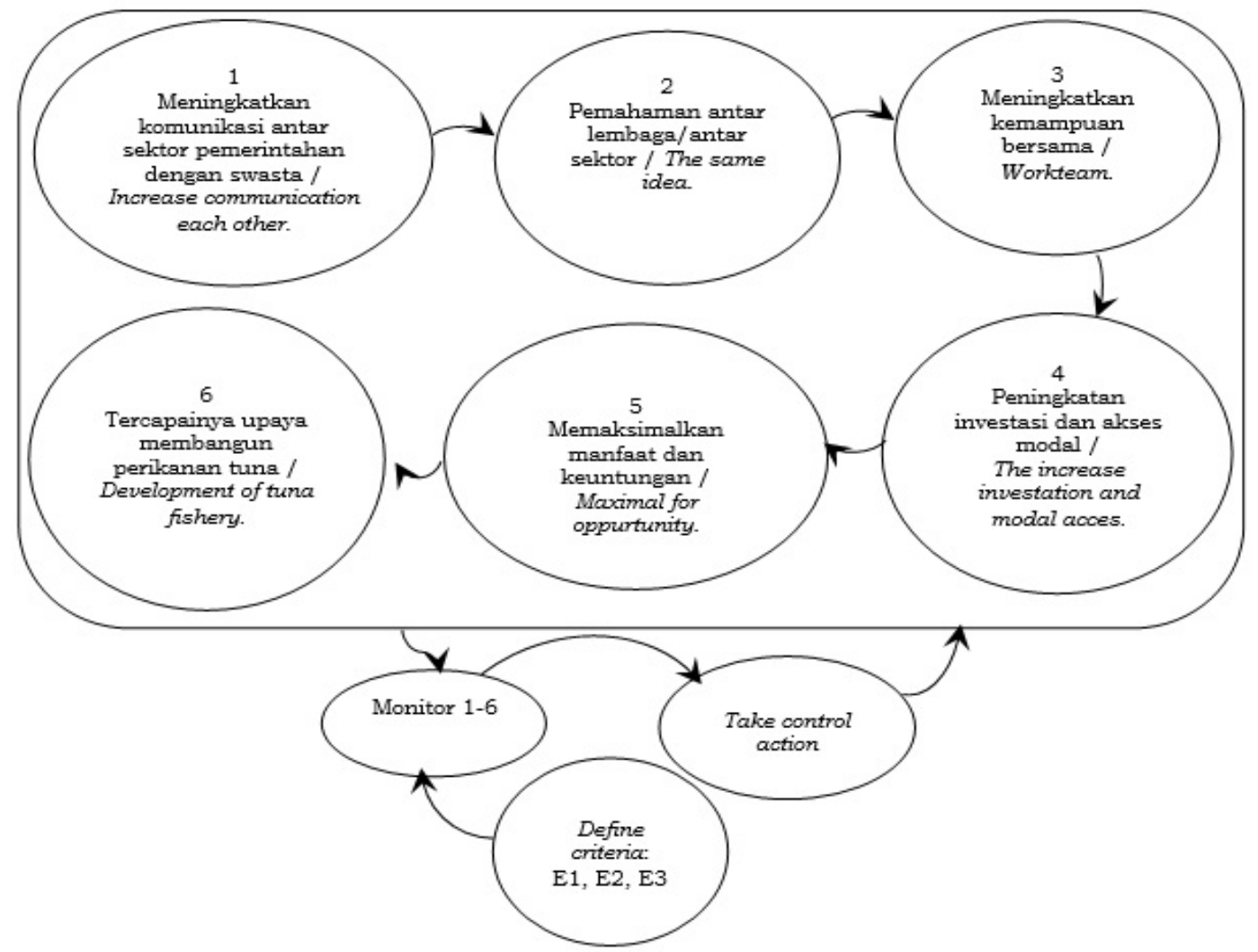

Gambar 3. Model konseptual kelembagaan di PPS Bungus 


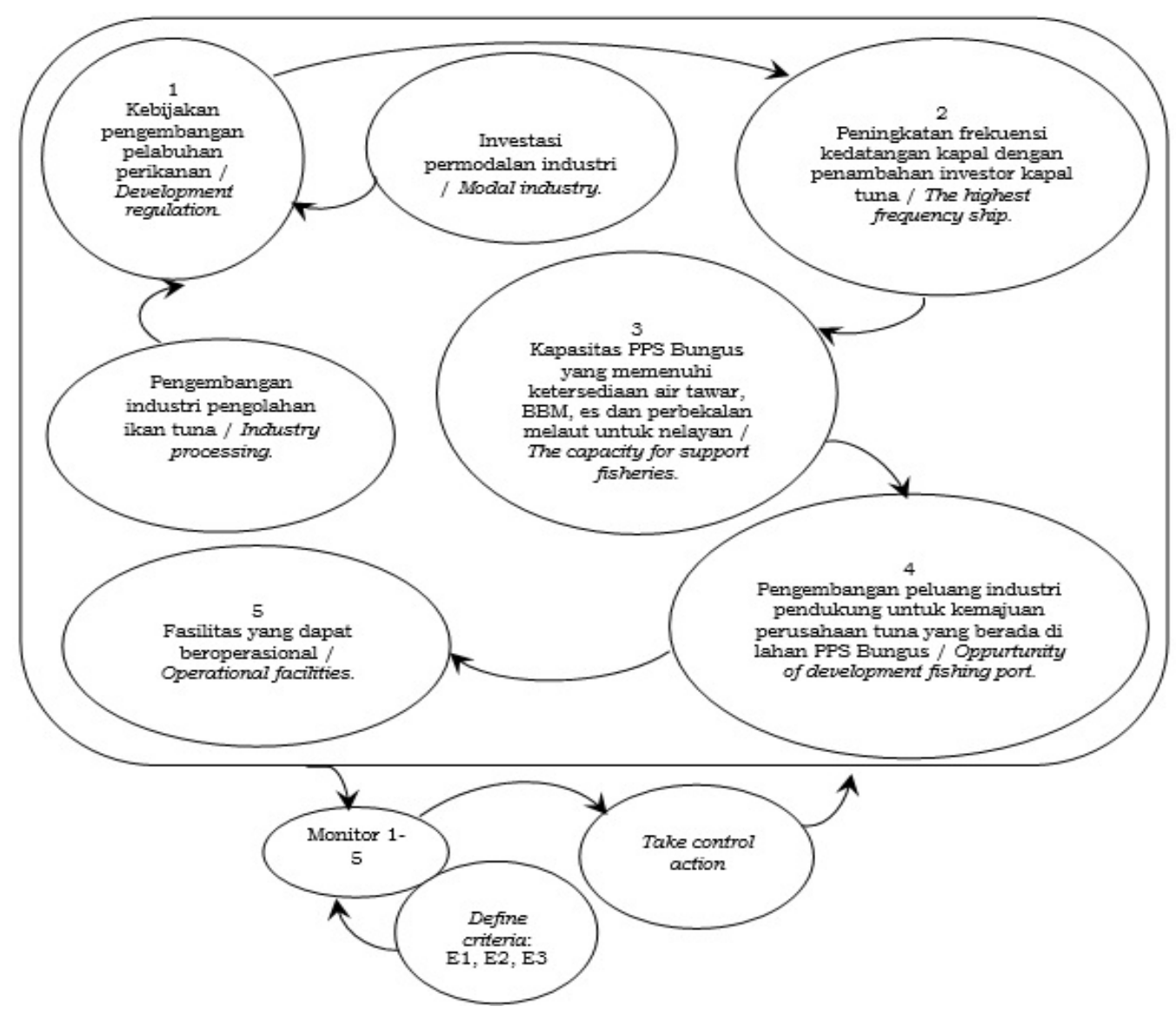

Gambar 4. Model konseptual kegiatan menarik kapal tuna masuk ke PPS Bungus

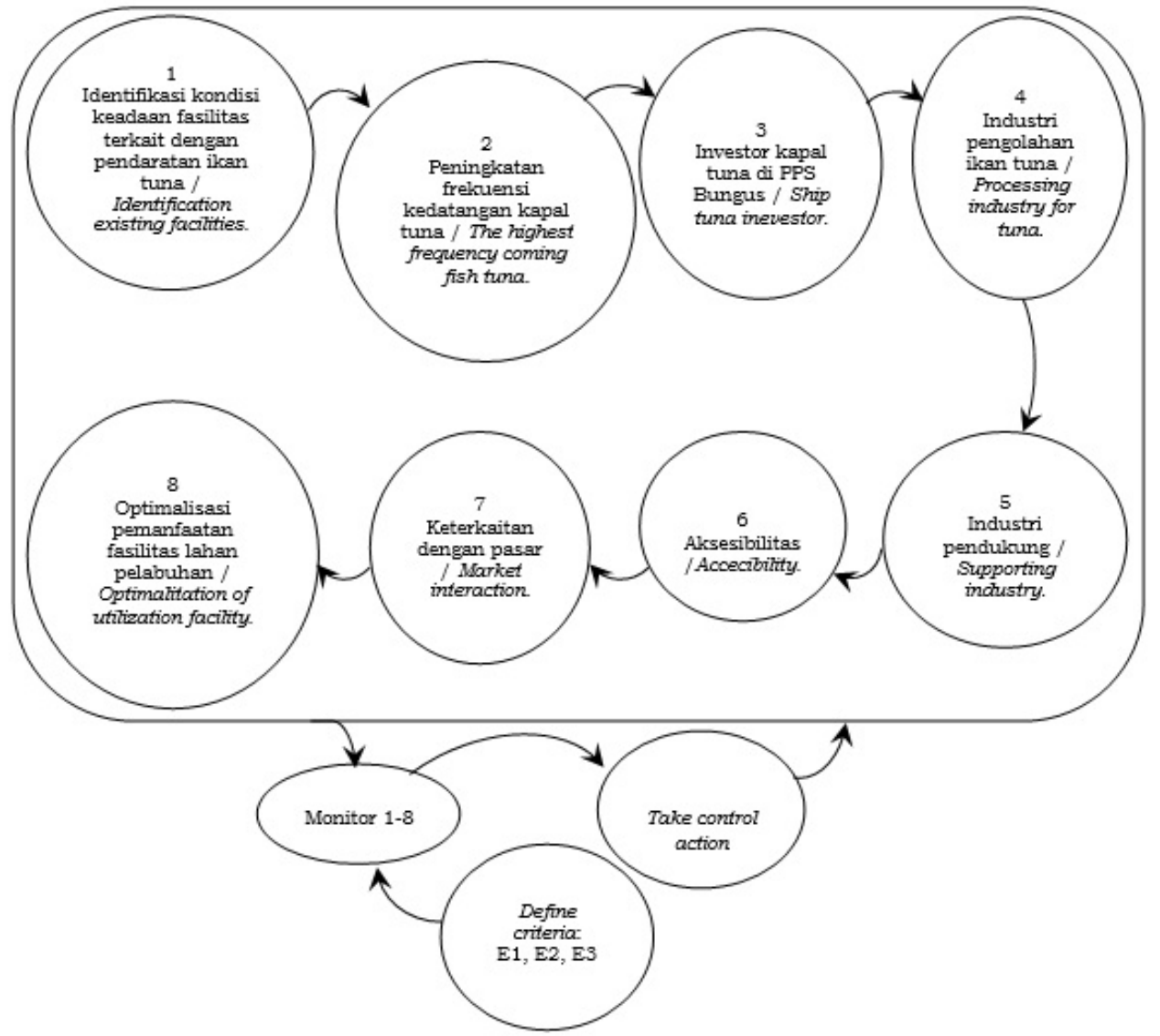

Gambar 5. Model konseptual optimalisasi pemanfaatan fasilitas pendaratan tuna di PPS Bungus 


\section{KESIMPULAN DAN SARAN}

\section{Kesimpulan}

Hasil evaluasi terhadap kinerja PPS Bungus diperoleh berbagai permasalahan yang dapat dikelompokkan dalam aspek sumberdaya manusia dan kelembagaan, aspek pelayanan dan aspek fasilitas. Root definitions ditetapkan untuk mengatasi permasalahan yang ada yaitu root definition 1, peningkatan kualitas sumberdaya manusia pengelola pelabuhan untuk dapat memberikan pelayanan yang baik melalui peningkatan kapasitas dan kapabilitas sumberdaya manusia; root definition 2, peningkatan koordinasiantarlembaga/antar sektor untuk dapat melakukan pengembangan secara integrasi; root definition 3, peningkatan/ menarik kapal tuna untuk masuk ke PPS Bungus melalui kesiapan fasilitas pelabuhan agar tercapainya optimalisasi penggunaan fasilitas sebagai pusat pendaratan ikan tuna; dan root definition 4, pengembangan dan pengoptimalisasikan lahan pelabuhan untuk industri serta penyediaan fasilitas melalui kerjasama dengan pihak swasta. Model konseptual dibuat berdasarkan root definitions yang telah ditetapkan.

\section{Saran}

Sistem pengembangan pelabuhan perikanan yang baik dapat tercapai secara optimal apabila melibatkan stakeholder. Keterlibatan secara aktif dari seluruh pihak sangat diperlukan untuk menjalankan model konseptual yang disarankan.

\section{DAFTAR PUSTAKA}

Checkland P, Poulter J. 2006. Learning for Action: A Short Definitive Account of Soft System Methodology and its use for Practitioners, Teachers and Students, John Wiley and S o n s, Ltd. Chichester. P. England.

Diniah, Sobari MP, Seftian D. 2012. Pelayanan pelabuhan perikanan nusantara (PPN) terhadap kebutuhan operasi penangkapan ikan. Jurnal Kebijakan Sosial Ekonomi Kelautan dan Perikanan. 2: 41-49.

Hidayatullah H. 2011. SSM sebuah pendekatan holistik untuk kegiatan aksi (learning for actions). Jurnal Sosiologi Islam. 1 : 109-116.

Iskandar HB, Wahyudi AG, Nurani WT. 2010.
Pre requisite study on application of hazard analysis critical control point management system for on board tuna longliner. Indonesian Fisheries Research Journal. 17 : 111-117.

Kresnanto NJ. 2004. Analisis kinerja dan pengembangan pelabuhan perikanan nusantara Pekalongan di Kota Pekalongan. [Tesis]. Semarang: Universitas Diponegoro.

Lubis E. 2011. Kajian peran strategis pelabuhan perikanan terhadap pengembangan perikanan laut. Akuatik Jurnal Sumberdaya Perairan. $5: 1-7$.

Lubis E, Pane BA. 2012. An model optimum of fish auction in Indonesia fishing ports in according with the characteristics of fisherman. Original Paper Journal of Coastal Development. 15 : 282-296.

Nurani WT, Lubis E, Haluan J, Saad S. 2010. Analysis of fishing ports to support the development of tuna fisheries in the South Coast of Java. Indonesian Fisheries Research Journal. 16 : 69-78.

Nurani WT, Lubis E, Haluan J, Saad S. 2010. Development of tuna fisheries management strategis for the Southern Coast of Java: an application of interpretative structural modeling. Indonesian Fisheries Research Journal. 17 : 101-110.

Peraturan Menteri Kelautan dan Perikanan Republik Indonesia. Nomor PER.30/ MEN/2012.

Pelabuhan Perikanan Samudera Bungus. 2016. Laporan Tahunan 2015. Padang.

Rahmah A, Nurani WT, Wisudo HS, Zulbainarni N. 2013. Management of troll fisheries with fish aggregating Pondokdadap Sendang Biru, Malang. Jurnal Teknologi Perikanan dan Kelautan. 4 : 73-88.

Rahmawati W, Suryono A, Siswidiyanto. 2014. Pengembangan pelabuhan perikanan dalam rencana penyerapan tenaga kerja masyarakat pesisir (Studi pada kantor Pelabuhan Perikanan Nusantara Brondong Kabupaten Lamongan). Jurnal Administrasi Publik. 2 : 367-373.

Ruswandi A, Dewi G. 2013. Strategi pengembangan investasi di sekitar Pelabuhan Perikanan Tipe B di Jawa Barat. Jurnal Akuatika. 4 : 89-101.

Riyanto A, Eriyatno, Pasaribu B, Maulana A. 2013. Model of outsourcing policy institutional integration in industrial relation perspective using soft system 
methodology: case study in Bekasi regency-Indonesia. International Journal of Information Technology and Business Management. 18 : 24-34. 